\title{
O saber e o sabor de Rubem Braga
}

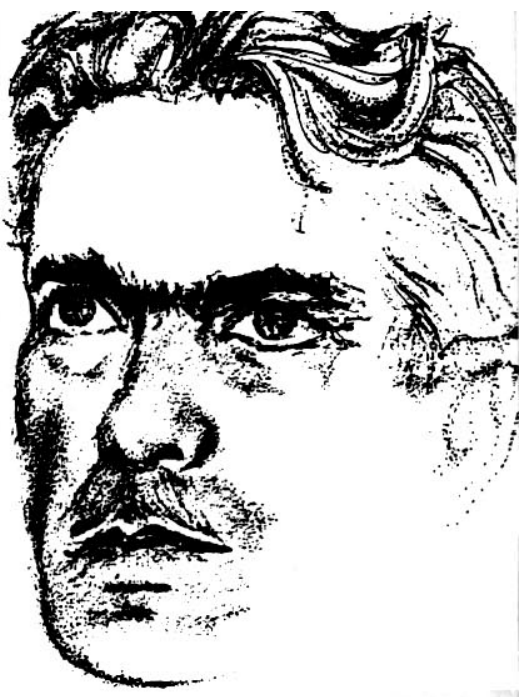

Aubem Braga, em desenho de Maria Mynsen

\section{Otto Lara Resende}

Uma vez um amigo meu redigiu um texto que devia interpretar a atitude de alguns intelectuais, jornalistas e escritores. Isso tem muito tempo. Obra comum, de muitos autores, buscando o consenso, acabou não saindo. Como todos tinham redação própria, todos meteram a sua colher de pau. Na tentativa de parecer texto de todos, virou texto de ninguém.

Mas o texto agarrou mesmo foi no Rubem Braga. Já nessa altura, o Rubem andava com uma confessada antipatia por manifestos ou por qualquer iniciativa que, sendo coletiva, deveria contar com o seu apoio e o seu nome. Não foi por isso, porém, que a tal declaração não chegou a vir a público.

$O$ Rubem até que estava de acordo e queria se manifestar. Para ele o que era difícil era aceitar os termos em que o documento vinha redigido. Sem saber quem era o autor daquela redação que pretendia ser final, ele leu, refletiu e calou. "Está muito gritado", disse ele.

Não queria fazer sugestōes nem tomar a si aquela tarefa ingente. Apertado pelo meu insistente saca-rolha, me disse que o texto tinha adjetivo demais. E também dizia mais do que era preciso. Dizer demais, com ênfase, é tão ruim, ou pior, do que dizer de menos. Em suma, era preciso baixar o tom, ir direto ao alvo, mas a essa altura ele já estava enjoado do assunto e preferia dizer por conta própria o que pensava.

Já nem sei se disse. Pode ser que sim, porque o Rubem não era de guardar o que pensava, sobretudo quando se tratava de assunto capaz de mobilizá-lo até levá-lo à hipótese de assinar um documento comum, ou coletivo. Conto esta passagem, como podia contar outras, porque me parece expressiva do jeito de ser de Rubem Braga.

Jeito de ser e jeito de escrever. Posso dizer uma coisa e outra. Ou uma coisa, ou outra. Ou as duas. Dá no mesmo. Porque Rubem Braga só tinha jeito de Rubem Braga. Um jeito só, fosse para o que fosse. Escritor, o jeito de escrever de Rubem Braga era o seu jeito de viver. Seu jeito de ser. Acho que nunca lhe passou pela cabeça a idéia de enfeitar o que escrevia. A rigor, não escrevia, no sentido em que "escrever" significa a busca de uma maneira de ser. De um estilo.

Não é outra a razão por que os textos do Rubem não parecem escritos. Fluem, vivem. Claro que ele sofria e às vezes, para conseguir escrever o que queria, levava horas e horas atrás da expressão certa. Podia também ocorrer que o texto saísse espontâneo, com a força das coisas que nascem porque precisam nascer.

Mas Rubem Braga não buscava o decorativo. Não ornamentava o que tinha a dizer. Nem se paramentava com a intenção de valorizar o que dizia. O que escrevia cra cem por cento Rubem Braga. Não podia ser diferente. Nem por isso se dirá que ele não tem uma forma personalíssima de escrever. O que ele diz só ele diz da forma por que diz.

Está aqui a razão do sucesso de Rubem Braga como cronista. Se alguém se dispuser a analisar a sua prosa ao longo dos quase sessenta anos em que esteve presente nos jornais; na certa vai verificar que Rubem mudou, sim. Mudou aqui e ali, mas sempre no sentido de reforçar a sua maneira de ser. Se aparou um ou outro excesso, só o aparou para o texto chegar à perfeita sintonia com o autor.
OTTO LARA RESENDE é, segundo ele próprio, "jornalista, escritor. 68 anos. mineiro". 


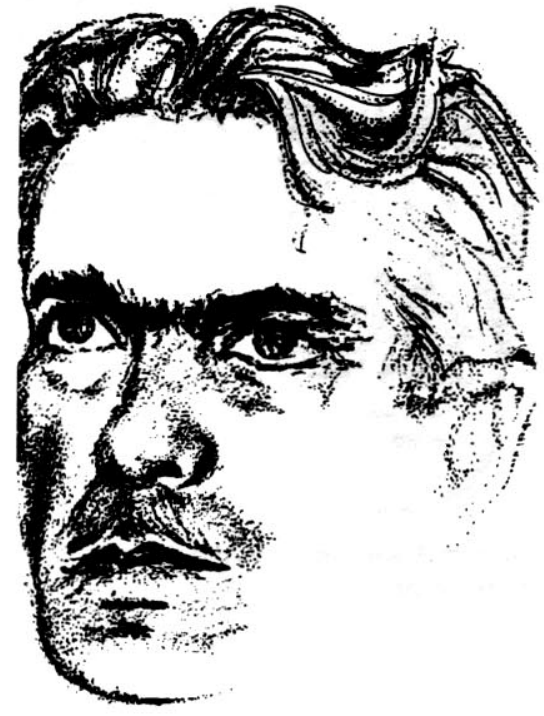

Suas primeiras crônicas, publicadas em Belo Horizonte, datam do princípio de 1932. Rubem tinha 19 anos. Mas já era Rubem Braga, isto é, tinha o seu jeito de escrever. O seu jeito de ser, pessoal e intransferível. Por isso sua presença chamou logo a atenção e fez sucesso. Ou seja, foi entendido. Atingiu o alvo, com as palavras exatas, sem nenhuma necessidade de artifício.

Muito bem dotado, sensibilidade alerta, com gosto pelas artes plásticas e até com algum jeito para o desenho, Rubem nada tinha de versátil. Podia ter sido poeta. Poeta em verso porque nunca foi outra coisa senão poeta - em prosa, a melhor prosa lírica do Brasil, na opinião de Manuel Bandeira. Chegou a fazer poemas e publicou, ou deixou que publicassem os seus versos.

Aceitou que publicassem porque a edição tinha um certo jeito de ser que era bem à maneira de Rubem Braga. Edição pobrezinha, feita em Pernambuco, trazia no título, se não me engano, a sobriedade do autor - Livro de versos de Rubem Braga. Era a sua obra completa de poeta bissexto. Sem se levar a sério como poeta, já que não tinha oficina montada, como disse Manuel Bandeira, Rubem gostou do livrinho.

Tendo começado a escrever muito cedo e escrevendo sempre para o jornal, é provável que Rubem Braga não tenha tido de início o propósito de fazer uma obra literária. Seus livros foram acontecendo, à medida que aparecia um editor. Com o tempo, editor $\mathrm{e}$ leitores não faltavam. Pelo contrário. Até pediam um novo livro de Rubem Braga.

Tendo sido editor ele mesmo, ainda assim não procurou impingir ao púbiico os seus livros. Não tinha pressa. Nem cuidava de arrumar os originais como seria preciso. Mais de uma vez ele me deu um monte de recortes de jornais para que eu ajudasse na seleção das crônicas. Foi o caso, por exemplo, de As boas coisas da vida, seu último livro.

Fiz uma primeira leitura, separei os textos que a meu ver deviam ser aproveitados e sugeri que mandassem bater tudo à máquina. Era como fazia Carlos Drummond de Andrade, que organizava os originais de um livro de crônicas de maneira impecável. Rubem era o contrário. A custo se dispunha a mudar um título apressado, ou a cortar uma frase ou uma palavra que, cabíveis no jornal, não tinham razão de entrar no livro.

Mais de uma vez sugeri ao Rubem que escrevesse um livro com as suas reminiscências de Cachoeiro de Itapemirim. Como declarou numa entrevista, não tinha a intenção de escrever memórias. Mas gostava de narrativas autobiográficas que focalizam os primeiros anos da vida. A infância era a seu ver o período mais interessante do ponto de vista literário. E o mais fácil. Vida de menino rende sempre um bom texto, dizia.

Eu discordava e discordo. E insistia no seu livro de memórias infantis. Ultimamente, já não lhe pedia que escrevesse um livro. Deixasse apenas juntar as crônicas que escreveu sobre a sua própria infância. Com uns poucos retoques, ou sem nenhum retoque, daria um livro delicioso, de interesse permanente. Rubem nunca se animou a preparar uma seleção assim. Não tenho dúvida, porém, que essa antologia, hoje dispersa, um dia existirá e terá lugar definitivo em nossa literatura.

Homem denso, forte caráter, Rubem Braga está inteiro em cada crônica ou em cada livro que publicou. Está inteiro em cada frase. Escrevendo como quem respira, não sabia senão dar notícia do mundo que passou por sua sensibilidade. A vida lhe chegava por via direta, sem intermediação. O que sabia lhe vinha das fontes de sua rica experiência pessoal. Era um saber que passava mais pelos sentidos do que pelo conhecimento intelectual.

Nisso reside em boa parte o encanto do cronisía. O sabor de sua prosa vem do fato de que ele só fala do que conhece, do que provou. Andou muito Rubem Braga. Viajou por todo o Brasil. Viveu em Porto Alegre, em São Paulo e no Recife. Saiu de Cachoeiro para Niterói, ainda adolescente. Estudou e trabalhou no Rio e em Belo Horizonte. Nunca recusou uma viagem ou uma aventura.

Mal começava a sua vida de repórter e foi cobrir a Revolução de 1932, junto às tropas mineiras no Túnel da Mantiqueira. Mais tarde, durante a guerra, disputou e conseguiu o lugar de correspondente na Itália, junto à FEB. Como sempre, o senso de humor não excluía o temperamento melancólico. As horas de perigo e tensão, como ele próprio dizia, espantavam as tristezas para o fundo do coração.

No fundo do coração de Rubem Braga estava mesmo era o tesouro inesgotável da sua infância. Tudo o que ele viu e provou ao longo de toda a sua vida, provou e viu a partir de uma medida que acompanhou o menino de Cachoeiro de Itapemirim. Esta foi sempre a sua fonte genuína. Dela é que nasce e toma forma o universo lírico do grande prosador Rubem Braga.

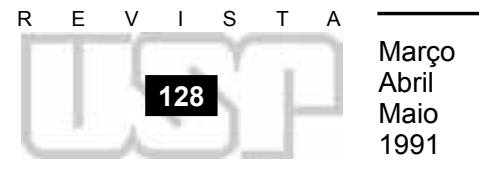

